\title{
Placing of Environment- Behaviour (E.B) Studies in Training of Environmental Design in Iran
}

\author{
Reza Naghdbishi ${ }^{1}$, Hamid Naghdbishi ${ }^{2}$, Sepehr Adibzadeh ${ }^{1}$ \\ ${ }^{1}$ Department of Architecture, Islamic Azad University, Roudehen Branch, Tehran, Iran \\ ${ }^{2}$ Department of Industrial Design, International Campus of Kish, University of Tehran, Kish, Iran
}

Email address:

reza.naghdbishi@riau.ac.ir (R. Naghdbishi), hamid.naghdbishi@gmail.com (H. Naghdbishi), adib.sepehr@yahoo.com (S. Adibzadeh)

\section{To cite this article:}

Reza Naghdbishi, Hamid Naghdbishi, Sepehr Adibzadeh. Placing of Environment- Behaviour (E.B) Studies in Training of Environmental Design in Iran. Education Journal. Special Issue: Interdisciplinary Researches in Environmental Design Education.

Vol. 4, No. 1-2, 2015, pp. 16-21. doi: 10.11648/j.edu.s.2015040102.13

\begin{abstract}
The present article is intended to interpret the state and position of Environment- Behavior (E.B) studies in architectural training in Iran (Contemporary era) in order to examine the status quo along with expressing the deficiencies in the path of prediction of future measures as an interdisciplinary approach. On the other hand, the analysis of the existing literature in Environment- Behavior (E.B) knowledge in environmental design will be also as other part of these efforts for application in the field of training of architecture. The method that was used in this research is to move from descriptive analysis approach toward inductive analysis. The results of this article include identifying the existing approaches in environmental design knowledge in Iran in which it deals with proposing suggestions for developing E.B field to use this method in training of environmental design at theoretical level in Iran.
\end{abstract}

Keywords: Training of Environmental Design, Architecture Knowledge, Environment- Behavior (E.B) Studies, Strategies and Measures, Interdisciplinary approach

\section{Introduction}

Application of design knowledge has being raised as a challenge for researchers and designers. Knowledge of architecture includes a range of procedures and methods to performing special tasks, structural and functional relations between objects and suitable usage for past experiences to new situations. It's inevitable for reliance on a structure that affects Infrastructures and components of architectural design and also in architectural training. Addressing the architectural knowledge as a content and criterion to proceed in design process, plays an important role in area of Architectural education because "Use of design knowledge, as an inevitable necessity, can be an appropriate instrument to reduce wrongs and saving time. On the other side, the knowledge in western arena confronts designers with aggregate information that can be reason for confusion of them, if they don't recognize type and place of knowledge. Therefore, it's necessary to identify the knowledge that may be highly available in a particular subject for designers, otherwise, it was misleading." [1] Since "Architectural design is assumed as a multidimensional and complex process including combination of knowledge and creativity" [2] thus identifying involved characters in understanding, analysis and product of the concerned architectural knowledge is incorporated as a basic component of an accurate process in architectural design and its training. Also, before playing role as the matter of architecture in architectural training, it's appertained to concept of Education in which this activity in context of society, particularly in period that it has changes and swings, may be accompanied by the several tastes and opinions and the architectural design that is not excluded from this subjects.

According to Tasdighi and Tasdighi [3], interdisciplinary research, considerably developed as a ways for leaving out of the crisis of reduced integration and indifference about reality in human science and also resolving the human unknown parameters. These researches are collected by using of several disciplines and then they acquired a more complete perception of phenomena. Characteristics of a successful interdisciplinary research include an appropriate use from each of the disciplines as an authoritative reference of knowledge. 


\section{Scientific Approaches to Knowledge of Architecture}

According to Cross [4] study in the "design methods movement" of the 1960s, the conference on Design Methods was held in London in September 1962 and it was generally regarded as the event which marked the launch of design methodology as a subject or field inquiry. The origin of this emergence of new design methods in the 1960s was laid in the application of novel, scientific and computational methods to the novel and pressing problems of the Second World War. He has proposed distinct definitions for Scientific Design, Design Science and Science of Design. He argues [4] that the Scientific Design refers to modern, industrialized design - as distinct from pre-industrial, craft-oriented design-based on scientific knowledge but by utilizing a mixture of both intuitive and non-intuitive design methods. Scientific design is probably not a controversial concept, but merely a reflection of the reality of modern design practice, Design Science refers to an explicitly organized, rational and wholly systematic approaches to design ; not just the utilization of scientific knowledge of artifacts but design in some sense as a scientific activity per se. This is certainly a controversial concept, challenged by many designers and design theorists and Science of Design refers to that body of work which attempts to improve our understanding of design through scientific methods of investigation.

In this article, author's aim will be followed at area of "Science of Design" by inquiry and investigation for "Environment-Behavior studies" as a basic structure for definition an architectural knowledge to have a scientific approach toward architectural design and training. On the other hand, according to an interdisciplinary approach it is another matter that aided to optimization of the training procedure in architectural education. For this reason, Horri [5] argues that nowadays, the process of research isn't under condition that a discipline is able to gain and seek whole solution for its special problems within their own borders exclusively, so benefiting from the result of other field is mandatory. According to Tasdighi and Tasdighi [3], interdisciplinary research was considerably developed as a ways for leaving the crisis of reduced integration and in difference about reality in human science, also for resolving the human unknown parameters.

These researches are shaped by using of several disciplines as a result they may have a more complete perception of phenomena. Characteristics of a successful interdisciplinary research is an appropriate employing each of the disciplines as an authoritative reference of knowledge and at the same time, Spiel [6] believes that interdisciplinary studies include researches that are shaped within a unified subject and in solutions resultant from different sciences and have require to an interaction between various knowledge. In such studies researches are not affected by a method or specific viewpoint thus a more complete understanding may emerge from phenomena .In this research, Integration of Behavioral Science and Architectural Design was pursued for achieving a specific structure based on scientific approach to Environment-Behavior knowledge.

\section{Theoretical Approaches on Design Knowledge}

The domain of knowledge in architectural design has varied due to inherent features and dependence on various factors because "architecture is actually a pluriaxial and multidimensional issue. This is why realization of architecture requires to a series of knowledge and various sciences" [7]. Accordingly, classification of design knowledge domain is expressible based on different viewpoints and it is evident antiquity in Vitruvius's book [8], (Ten Books on Architecture). He believes that "the Architect should be equipped with knowledge of many branches of study and various kinds of learning therefore based on his judgment all work done by the other should be put into test. This knowledge is the product of practice and theory." According to Alaie [7] Vitruvius defines the need of architect to the range of technical cases about conceptual matters and includes five categories in his statements: certainly learning, understanding and perception, practice and experience and imitation within Study and individual knowledge.

\section{Knowledge of Environmental Design Training in Iran}

The major existing knowledge about environmental design in Iran is based on the structures that have formed before and after Cultural Revolution. Before the Cultural Revolution, these structures have been accompanied with reluctance and overlooking by the educational authorities toward subject of theoretical application and in the period after Cultural Revolution and with respect to passing over three decades of its design and execution, it could not be adequately coordinated with the contemporary developments at global and regional scales. Based on classification that has been carried out by Naghdbishi [9] regarding content of architecture knowledge about training of environmental design in Iranian contemporary period (since 1934), it could be divided into five parts in the field of knowledge of Iranian environmental design including 1) interpretative designs and skills in architecture; 2) Architecture theoretical bases; 3) Technique of construction; 4) Complementary knowledge (optional lessons); and 5) Section of general perceptions (society, religion, skill, and policy etc.). Accordingly, despite of development and plurality of knowledge extent in various fields, deficiency of theoretical knowledge is posited generally under title of 'Theoretical bases' in Iran and with respect to multiplicity and variety of the conducted theoretical developments in the world, this fact is visible. In this course, Karimi Moshaver [10] also argues that 'The problem of workshop training method in Iran is in that the position of design knowledge is not identified in educational process and the decisions are usually made according to 
personal views from the teacher of the given lesson that could not be adequate for proper design. For this reason, it requires primary to pay attention to producing design knowledge in workshop training.' Similarly, he [10] maintains that one of the today problems in training of environmental design is that there is no reference book for training of architectural design and for this reason the designers could not so far write their knowledge like other sciences in this regard. For this reason, perceiving the subjects in the field of architectural design can be relatively difficult for instructors of architectural design as well as learners.

Therefore, optimization and transformation in educational methods will be accompanied with several developments in approaches toward social sciences, psychology, economics, and environmental planning etc. to form process of training and thus it requires the presence of an interdisciplinary approach toward training of environmental design followed by creation of strategies for systematization of environmental design training and formation of architectural product in light of pivotal theory with its co-linked discipline where the moving in this path needs to description, definition, interpretation, and hermeneutics of the left heritage from architecture with appropriate researching and educational methods and with reliance on upstream documents and rules in order to coordinate further educational goals with these regulations and to find roots of problems and bottlenecks in the field of architectural training thereby one could compensate for the existing deficiencies in art training fields particularly the architecture and to accelerate in achieving appropriate and defensible position possibly in the future [11] For this purpose, as one of the most frequently used fields of environmental design knowledge, E.B studies may serve as one of the strategies for exit from the aforesaid deficiencies' thereby it can be employed for optimization of teaching methods of environmental designs and thus improvement the quality of architectural spaces.

\section{Environment- Behavior Knowledge}

E.B that is also called the environmental design research is the study of the common relationships among people and physical environments of functions for optimization of quality of life by environmental policies, planning, and design. As a systematic field of study on this function, these studies were started in 1950s. There are several main fields of environment within architecture extent. The behavioral researches include developing the theory about relationship among architecture and human's behavior, substantive research on subjects of place, human groups as well as behavioral and social subjects and investigation into processes, methods, and functions [12].

\subsection{Scopes and Scales}

The limit of E.B research is wide. Its participants and effects are different and various. The existing researches have been implemented within range of human sciences at studied scale in interior design through studies of social geography and urban anthropology at regional scale. Its participants include all of experts in the fields of behavioral and social sciences as well as professionals in all design and planning occupations [12].

In Moor's opinion [12], recognition the distinction among basic research, applied research, and research application can be helpful. The E.B research consists of the behavior of knowledge organization and discovery of processes and systems to perceive E.B interactions and developing theory of environment regarding human's activities. On the other hand, E.B applied research is concerned with giving answers to special questions about subject of immediate design and finally E.B research is employed by means of both basic and applied researches for specific environmental subjects.

The E.B researches belong to all scales of analysis ranging from macro- scale in large geographical zones, cities, and neighbors to micro-scale of objects in everyday physical environment including street signs and furniture and construction materials. The general theories about E.B relations require considering the behavioral responses at three scales: macro, meso, and micro. At macro scale, this theory is required considering the group behavior inside large scale environments (urban regions, landscapes, societies, cities, and geographical zones).

In Meso scale, it is required to address behavioral and group behavior inside environments at meso scale (buildings and outdoor spaces) while at micro scale, it should be assumed for individual behavior and environmental units (lighting in surroundings, noise, stimulation, and complexity). Despite of the fact that architectural requirements have been focused on meso scale, these three scales should receive the equal emphasis in considerations of general relationship among behavior and environment [12].

\subsection{Interactional Approach}

Like what it occurred in link and interaction between behavioral sciences and in design field during 1960s, E.B knowledge as a subset of behavioral sciences, is exposed to several challenges in applied accompaniment with creating structure to design organization. From the viewpoint of Razjooyan [13], the most major problems of this coalition can be assumed in two subjects of difference between interests and differences in methods of storage of knowledge among designers and scientists. Lang [14] believes that some of architects feel that inquiry in social beliefs and ideas of designers, design based on research findings, using the controlled and repeatable observations, adaption of logical analysis, and belief in regular research standards may threaten their professions and it seems that the same feeling causes continuous confusion and wandering of professional designers toward activities, goals, and attitudes of scientists about creativity in design.

Ittelson et al [15] argue that the physical structures of psychology of inhabitants have been always formally recognized in architecture but this issue has been mainly assumed in applied psychology.

But, all of these challenges in interpretation of literature in 
study of E.B research for design techniques are led to some profitable uses in the field of environmental design that is mentioned as a requisite for research.

\section{Position of E.B Knowledge in Iran}

In Iran, E.B knowledge was started with mild tones and slow steps. The efforts made by the architectural instructors, who tried to transfer the resulting theoretical literature from behavioral sciences to the field of design instructions, included the major part of this onset. With publication of an article titled 'A review on coalition of architecture with behavioral sciences during recent half century', Mahmoud Razjooyan [13] tried to start this introduction. Afterwards, Shahrnaz Mortazavi [16] as a researcher of psychology published book of 'Environmental psychology and its application'. In fact, this was one of the basic steps taken to introduce the wide field of behavioral sciences and E.B studies in order to upgrade environmental design knowledge in Iran. During this year, translation of book of 'The hidden dimension' written by Edward T Hall [17], which was translated by Manoochehr Tabibian posited several approaches in the fields of cross- cultural studies. Coincide with these activities, the Iranian students, who studied abroad like Motalebi [18] paid attention to this field as the researching platform of their work. In the field of policymaker organizations, Ministry of Sciences, Researches, and Technology embedded the course of 'Environmental psychology' into the educational structure of teaching this lesson at Master's Degree. Based on this study, Motalebi [19] published an article under title of 'Environmental psychology a new knowledge to serve in architecture and urbanism'. The comparative studies were conducted by Razjooyan [20] among fields of Islamic architecture and environmental psychology as well. Translation the book of John Lang [21] by Einifar as well as translation of book of Altman [22] by Namazian may be posited as one of the other basic backgrounds in the field of E.B studies knowledge. Thesis in which it has been dealt with architecture in doctorate degree formed and prepared at this period. Out of these thesis, Falahat [23] dealt with sense of place and theories of David Canter and also Kamelnia [24] studied the role of behavioral sciences in community architecture. Moreover, holding of some workshop to deal with application of behavioral sciences in architecture [19] and holding a conference with the presence of John Lang in Iran are proposed as signs of belonging to E.B field. Translation of the book of 'Meaning of the built environment' from Amos Rappaport [25], 'Environmental psychology' from Francis T. McAndrew [26], 'The language of space' of Bryan Lawson [27], and writing the books of 'Environmental psychology' [28], and 'Community architecture, from theory to practice' [29], and codification of doctoral treatise under title of 'Training of architecture with focus on design process from viewpoint of behavioral sciences ' [30] are the latest activities in these fields.

\section{Discussion and Conclusion}

There are many common points in educational methods for teaching of students in various architecture schools particularly in lessons, which deal with training of architectural design. Nonetheless, although design is deemed widely as a type of activity that is based on very different sciences ad factors, the adequate potential for the unified and comprehensive innovation may not be often easily provided.

These educational processes in architecture ranging from the most ancient approaches to the latest innovations for them are mainly based on a certain method (model) that covers variety and different forms of methods and models as well as the various and different paradigms and attitudes, the facilities and capabilities during the studied period, and sometimes a composition of several sciences and disciplines.

The most salient dimension of these educational processes is to attach a certain structure for furtherance of teaching system toward its favorable objectives without any thoughtful support and based on theory to recognize this method that is impossible to be acquired and when the subject of methodology is proposed in complex field of training architecture and architectural design, the importance of adaption of teaching method will be doubled due to its multidimensional characteristics. Likewise, the requirement for a platform based on design knowledge is tangible for optimal progress in education.

Based on the formed activities in the field of E.B knowledge in training of environmental design at Iran, it is inferred that the content approaches in this field can be divided into five parts.

According to review on these efforts, one can refer to these approaches in the extent of E.B knowledge, as follows: 1) Pioneer approaches, 2) Interdisciplinary approaches, 3) Theorist approaches, 4) Descriptive approaches, and 5) Cross cultural approaches. In Table (1), a group of these findings may be available.

What it inferred from analysis of these activities indicates that despite of all efforts, E.B knowledge has not been adequately addressed. While, these theories have been highly utilized to improve environmental design teaching methods as well as to upgrade the quality of life environments and increase the behavioral security in the contemporary world. Therefore, it seems based on the strategies, which are implied, this position may be further consolidated:

1- Writing and translation of primary sources in the field of E.B studies

2- Operationalizing theories of behavioral sciences in various fields of environmental design

3- Implementation of the relevant applied researches to teaching of environmental design

4- Paying attention to interdisciplinary approaches

5- Upgrading knowledge of environmental design in instructors in environmental and behavioral fields

6- Paying attention to E.B studies by educational policymaker organizations

7- Encouragement of students to advance the comparative 
research and design in architectural studios

8- Preparation of conditions for research in E.B fields for students
9- Allocation of the related theoretical lessons to E.B studies in educational structures in various educational courses.

Table 1. Environment-Behavior and environmental design studies, researches, and events with interdisciplinary educational approaches in Iran

\begin{tabular}{|c|c|c|c|}
\hline Year & Researcher/ author/ translator/ sponsor & Work/ event & Content approach \\
\hline 1996 & Mahmud Razjooyan & $\begin{array}{l}\text { Publication of article: Looking at coalition of architecture and } \\
\text { behavioural sciences during a half recent century }\end{array}$ & Pioneer \\
\hline 1997 & Shahrnaz Mortazavi & Writing book of environmental psychology and its application & Pioneer/ descriptive \\
\hline 1997 & Manoochehr Tabibian & Translation of book of hidden dimension written by Edward T Hall & Cross cultural \\
\hline 1998 & Ghasem Motalebi & $\begin{array}{l}\text { Codification of } \mathrm{PhD} \text { treatise in Sidney University with ecological } \\
\text { approach to architecture and urbanism }\end{array}$ & Pioneer/ theorist \\
\hline 1999 & $\begin{array}{l}\text { Ministry of Sciences, Researches \& } \\
\text { Technology }\end{array}$ & $\begin{array}{l}\text { Embedding lesson of environmental psychology into the MA } \\
\text { intermittent course of architecture }\end{array}$ & Interdisciplinary \\
\hline 2001 & Ghasem Motalebi & $\begin{array}{l}\text { Publication of article: The environmental psychology as a new } \\
\text { knowledge to serve in architecture and urbanism }\end{array}$ & Descriptive \\
\hline 2001 & Mahmud Razjooyan & $\begin{array}{l}\text { Publishing the article of the study among Islamic architecture and } \\
\text { environmental psychology }\end{array}$ & Interdisciplinary \\
\hline 2002 & Alireza Einifar & $\begin{array}{l}\text { Translation book of Creation of architecture theory, role of behavioural } \\
\text { sciences in environmental design written by John Lang }\end{array}$ & Descriptive \\
\hline 2003 & Ali Namazian & $\begin{array}{l}\text { Translation the book of environment and social behaviour written by } \\
\text { Irwin Altman }\end{array}$ & Descriptive \\
\hline 2005 & Farah Habib & $\begin{array}{l}\text { Translation the book of Concept of the built environment written by } \\
\text { Amos Rappaport }\end{array}$ & Descriptive \\
\hline 2008 & Hamed Kamelnia & $\begin{array}{l}\text { Codification of } \mathrm{PhD} \text { treatise titled the effect of environmental } \\
\text { psychology in participatory architecture Tehran University }\end{array}$ & Theorist \\
\hline 2008 & Gholamreza Mahmoodi & $\begin{array}{l}\text { Translation the book of environmental psychology written by Francis } T \\
\text { McEnroe }\end{array}$ & Descriptive \\
\hline 2011 & Ghasem Motalebi & $\begin{array}{l}\text { Holding the workshop titled architecture and behavioural sciences in } \\
\text { the fourth conference on architectural education Tehran University }\end{array}$ & Interdisciplinary \\
\hline 2012 & Alireza Einifar & Translation of book of language of space written by Bryan Lawson & Descriptive \\
\hline 2012 & ------ & $\begin{array}{l}\text { Presence of John Lang in Iran (conference on future of urban design } \\
\text { and architecture in Iran) }\end{array}$ & Pioneer \\
\hline 2012 & Jahanshah Pakzad- Hamideh Bozorg & Writing book of alphabet of environmental psychology for designers & Descriptive \\
\hline 2013 & $\begin{array}{l}\text { Seyed Gholamreza Islami- Hamed } \\
\text { Kamelnia }\end{array}$ & Publication of book of community architecture from theory to practice & Theorist \\
\hline
\end{tabular}

\section{References}

[1] H. Kamelnia, "Basic knowledge in architectural design" unpublished. Tehran, University of Tehran, Faculty of Architecture: PhD course in Architecture, 2004.

[2] S.J. Imami, “Architectural design as a meme”. In: Seyed. AS. Mahmoodi. Proceedings of the Second Conference on Architectural Education. Tehran, University of Tehran: Look at today's publication of the Faculty of Fine Arts, 2003.

[3] M.A. Tasdighi, F.Tasdighi, "Missing link Interdisciplinary Research in Higher Education System in 1404 A.H., (With emphasis on pathology)". In: First National Conference on Education in 1404 A.H. Tehran: Expediency Council Secretariat and Institute of Policy Science, Technology and Industry Sharif University of Technology, 2011.

[4] N. Cross, "Designerly Ways of Knowing", Springer Verlag, London, 2006.

[5] A. Horri, "Editor's Note". Journal of Book, No 3-4, pp. 52-67, fall and winter 1994.
[6] Seipel. M, "Interdisciplinary: An introduction". Truman state University, Kirksville, Missouri, 2006.

[7] A. Alaie, "Take the diversity of knowledge in architecture". Soffe, No 32, pp. 104-117, spring and summer 2001.

[8] Vitruvius Pollio, Marcus; (1914); Ten Books on Architecture; translated by Morris Hicky Morgan, Harvard University press, London.

[9] R. Naghdbishi, “Architectural Education after Iranian Cultural Revolution, (Unpublished Document) in PhD Course with I. Etesam". Tehran: Department of Art \& Architecture, Science and Research Branch, Islamic Azad University, Tehran, Iran, 2010.

[10] M. Karimi Moshaver, "Relation between learning styles and student performance in architecture design studios". In: Seyed. AS. Mahmoodi (Ed.), Proceedings of the Third Conference on Architectural Education. Tehran, Tehran University: Negahe Emruz publication of the Faculty of Fine Arts, 2009.

[11] SG. Islami, R. Naghdbishi, "Qualitative development of architecture in 1404 A.H.". In: First National Conference on Education in 1404. Tehran: Expediency Council Secretariat and Institute of Policy Science, Technology and Industry Sharif University of Technology, 2011. 
[12] Moore, Gary T, "New Directions for Environment-Behavior Research in Architecture" In Architectural Research, J.C. Synder (Eds.), Pp. 95-112, Van Nostrand Reinhold, New York, 1984.

[13] M. Razjouyan, "Looking at coalition of architecture and behavioral sciences during a half recent century". Soffe, No 6, pp. 35-47, 1996.

[14] J. Lang, "Creating architectural theory: the role of the behavioral sciences in environmental design". Van Nostrand Reinhold, 1987.

[15] W. H., Ittelson, H. M. Proshansky, L. G. Rivlin, G. H. Winkel, "An Introduction to Environmental Psychology". Holt, Rinehart and Winston, New York, 1974.

[16] S. Mortazavi, "Environmental psychology and its applications". Tehran: Beheshti University, 2001.

[17] Edward T. Hall, “The Hidden Dimension”. Anchor, 1990.

[18] Gh. Motalebi, "Pictures as Real Environments in Research". In M. A. Groves and S. Wong (Eds.). Design for people. Proceeding of PAPER96 Conference in Perth, Australia, Sydney: Edith Cowan University, pp. 141-156, 1996.

[19] Gh. Motalebi, "The environmental psychology as a new knowledge to use in architecture and urbanism". Honar-Ha-Ye-Ziba, No 10, pp. 52-67, 2001.

[20] M. Razjouyan, "A comprative study of Islamic architecture and environmental psychology". Soffe, No 32, pp. 118-131, spring and summer 2001.
[21] J. Lang, "Creating architectural theory: the role of the behavioral sciences in environmental design". A. Einifar (translator), University of Tehran, Tehran, 2002.

[22] I. Altman, "The environment and social behavior". Brooks/Cole Pub. Co, the University of Michigan, 1975.

[23] MS. Falahat, "The role of formal design in the sense of place: A comparative study of five contemporary traditional and innovative designed mosques in Tehran". PhD thesis, University of Tehran, Tehran, 2004.

[24] H. Kamelnia, "the effect of environmental psychology in participatory architecture", University of Tehran, $\mathrm{PhD}$ thesis, Tehran

[25] A. Rapoport, "The Meaning of the Built Environment: A Nonverbal Communication Approach". University of Arizona Press, 1990.

[26] Francis T. McAndrew, "Environmental psychology". Brooks/Cole Pub Co, 1992.

[27] B. Lawson, "Language of Space". Routledge, 2001.

[28] J. Pakzad, H. Bozorg. "alphabet of environmental psychology for designers”. Tehran: Arman-Shahr, 2012.

[29] SG. Islami, H. Kamelnia, "community architecture, from theory to practice". Tehran, University of Tehran, 2013.

[30] R. Naghdbishi, "Architectural Training with focus on design process from viewpoint of behavioral sciences". PhD thesis, Science and Research Branch, Islamic Azad University, Tehran, Iran, 2014. 